\title{
HIV testing and prevention among foreign- born Men Who have Sex with Men: an online survey from Sweden
}

\author{
Susanne Strömdahl ${ }^{1^{*}} \mathbb{D}$, Fredrik Liljeros ${ }^{2}$, Anna Ekéus Thorson ${ }^{1}$, Kristina Ingemarsdotter Persson ${ }^{1}$ and \\ Birger C. Forsberg ${ }^{1}$
}

\begin{abstract}
Background: There is an increasing trend toward international migration worldwide. With it comes a challenge for public health and public funded health care systems to meet the migrating population's health needs. Men who have sex with men are a key population for HIV, contributing an estimated 42\% of new HIV cases in Europe in 2013. HIV monitoring data suggest that foreign-born MSM are not only exposed to a high risk of HIV before migration but also while living in Sweden. The aim of this study is to examine HIV testing prevalence and uptake of HIV prevention interventions among foreign-born MSM living in Sweden.
\end{abstract}

Methods: A web survey available in English and Swedish was conducted from October 1 to October 30, 2013 via a Scandinavian Web community for Lesbian, Gay, Bisexual, Transgender and Intergender people. The web survey included modules on sociodemographics, condom use, sexual risk behaviour and HIV/STI testing experience. 244 eligible MSM participants born abroad and living in Sweden participated in the study. Descriptive and inferential analysis was performed.

Results: Half of the foreign-born MSM participants in this study had been tested for HIV during the last 12 months. Participants who had lived in Sweden less than or equal to 5 years were more likely to have been tested for HIV during the last 12 months. Having talked about HIV/STI with a prevention worker during the past year was associated with having been tested for HIV. Requested services among the majority of participants were HIV rapid test, anonymous HIV testing, HIV/STI testing outside of the health care setting and MSM-friendly clinics.

Conclusion: Efforts are needed to promote HIV testing among foreign-born MSM. Peer outreach, individual and group counselling may be preferred interventions to do so. In addition, it is critically important to increase HIV testing among foreign-born MSM who have lived in Sweden for more than five years. Further research should explore if scale up of implementation of requested services may increase frequency of HIV testing and detection of new cases linked to treatment among foreign-born MSM living in Sweden.

\section{Background}

Human migration has increased globally during the last decade. In 2013, 232 million people were estimated to be migrants, of whom $7 \%$ were estimated to be refugees. 72 million migrants resided in Europe 2013, of whom the majority were born in other European countries [1]. The United Nations (UN) defines a migrant as a person who changes his/her country of residence [1]. Sweden's

\footnotetext{
* Correspondence: susanne.stromdahl@ki.se

${ }^{1}$ Department of Public Health Sciences, Karolinska Institutet,

Tomtebodavägen 18a, floor 4, SE-171 77 Stockholm, Sweden

Full list of author information is available at the end of the article
}

population of 9.8 million included an estimated 1.6 million international migrants in 2014 [2]. About two-thirds of migrants globally travel from a low-income country to a high-income country [3]. Social and political factors also force people to migrate. One of these factors is that in parts of the world people are persecuted for their sexual behaviour as men who have sex with men (MSM) [4]. A current and future challenge for public health and public funded health care systems in high-income settings is to meet the migrating population's health needs.

MSM is a key population for HIV worldwide, contributing 42\% of estimated new HIV cases in Europe in 2013 
[5, 6]. In addition, 35\% of newly diagnosed HIV infections in 2013 were reported among migrants in Europe [7]. A recent study reports that the majority of migrants diagnosed with HIV within the last 5 years, living in Spain, the UK, Belgium, Portugal, Greece, Switzerland, the Netherlands, Italy and Germany probably acquired the disease in their current country of residence rather than their birth country [8]. Migrants in Europe also have a higher risk of late diagnosis of HIV than non-migrants [9].

HIV prevalence among MSM in Sweden was estimated at $2-6 \%$ in 2012 in comparison to $0.06 \%$ in the general population [10]. Between 2010-14, approximately 130 MSM per year were newly reported to be diagnosed with HIV in Sweden. Half of these are foreign-born MSM, which is an increase compared to $40 \%$ during the previous 5 year period (2005-2009) [11]. The proportion of newly diagnosed HIV cases among foreign-born MSM resulting from sex between men while in Sweden (as reported by the man himself) was $26 \%$ between 2005-2009 and increased to 36\% between 2010-2014 [11]. This indicates that foreign-born MSM are not only exposed to a high risk of HIV before migration but also while living in Sweden.

Sexual risk behaviour among MSM in Sweden has been studied in three earlier web-based banner surveys, a form of online convenience sampling, in 2006, 2008 and 2010 [12-14]. The two latter surveys included 15\% and 18\% foreign-born MSM [12, 14]. The 2008 study compared sexual risk behaviour for HIV/STI between MSM born in Sweden and abroad and found no difference in this particular convenience sample of MSM [14]. Other possible reasons for the elevated risk of acquiring HIV while in Sweden among foreign-born MSM is that they may be sexually active within a network where HIV/STI prevalence is higher [15]. Another reason could be that due to low uptake of regular HIV/STI-testing those persons may be undiagnosed while living with asymptomatic HIV/STI for longer time periods during which they are unaware of the risk of transmission.

Barriers to HIV testing among migrant MSM in the UK are reported to include fear of HIV, fear of legal consequences if living with HIV, stigma and discrimination, lack of culturally sensitive and competent services, language difficulties, lack of knowledge of health services and low priority given to HIV [16]. Foreign-born MSM who have lived for a long time in Sweden may overcome some of these barriers such as language, knowledge of health services and familiarity with rights, while other barriers such as stigma may remain.

The MSM population in Sweden and elsewhere lacks a sampling frame, which makes probability sampling difficult. Sampling strategies to recruit MSM includes respondent driven sampling within the social network of MSM [17]. However, foreign-born MSM are a heterogeneous group and not likely to be interconnected in merely one social network, rather several interlinked social networks. Another strategy is time location sampling from venues where foreign-born MSM meet, which could recruit foreign-born MSM living in metropolitan areas [18]. As foreign-born MSM represents a diverse group it is necessary to complement sampling strategies and studies to capture different parts of the population.

In conclusion, data suggest that the number of foreignborn MSM living in Sweden newly diagnosed with HIV is increasing. Improved knowledge of HIV-testing behaviour in this group is needed to ensure antiretroviral treatment for those living with HIV, which in addition is proven to lower HIV incidence by lowering community viral load [5]. The aim of this study is to examine HIV-testing prevalence and uptake of HIV prevention interventions including different HIV-testing options among foreign-born MSM living in Sweden.

\section{Methods}

\section{Study population, recruitment and setting}

A web survey, MSM 2013, available in English and Swedish was conducted from October 1 to October 30, 2013 via a Scandinavian Web community for Lesbian, Gay, Bisexual, Transgender and Intergender (LGBTI) people [19]. A detailed description of the study recruitment is available elsewhere [20]. Eligibility was defined by being registered as living in Sweden, 15 years or older and not registered as a woman on the Web community. Out of 52,979 eligible Web community members 14,514 were selected by stratified random sampling by age and county of residence to provide a sample that was representative of the Web community population. 2,751 MSM participated, of whom 289 reported being born abroad. Forty-five adopted MSM who were born abroad were excluded because they do not share the experiences of foreign-born migrants, having arrived in Sweden at a later age. This sampling strategy thus provided a sample of 244 MSM participants who are born abroad and live in Sweden which are included in the data analysis.

\section{Web survey design}

The questionnaire was developed by a multidisciplinary team including researchers, representatives of the Swedish Public Health Agency and seven different NGOs representing the MSM community. The web survey included modules on sociodemographics, condom use, sexual risk behaviour and HIV/STI testing experience. The survey was piloted with eleven MSM informants to ensure appropriateness, simple language and user friendliness.

\section{Statistical analysis}

The achieved sample of 244 foreign-born MSM is treated as a convenience sample in the data analysis. Descriptive and inferential data analysis was performed using SPSS 
Statistics v.22. Chi-square and $t$-test analyses were performed regarding sociodemographics, sexual identity and practice variables.

\section{Variables definitions}

Age was divided between young $(<25)$, middle age $(25-40)$ and older $(>40)$ men as previous findings show that the middle group test more frequently [12]. The majority of participants (57\%) had tertiary education and the education variable was dichotomized between tertiary education and lower. The dividing point for the number of years lived in Sweden was 5 years [21]. Participants having lived in Sweden for 5 years or less may be targeted by health interventions for newly arrived immigrants, while participants having lived in Sweden longer are not considered to belong to this group. This time frame is therefore of interest. The reason for moving to Sweden was dichotomized between refugees seeking asylum (21\%) and other reasons for migration (work, study or joining partner/family). Asylumseekers in Sweden are offered a set of health services, including HIV testing, which motivated this division [22]. Those having had unprotected anal intercourse (UAI) with a casual sex partner during the last twelve months (40\%) were compared to those who had not [23]. Similarly, having a steady sex partner in the past twelve months was divided between those with $(50 \%)$ and without. Participants having had unprotected sex with both male and female sex partners during the last twelve months (26\%) were compared to those reporting only unprotected sex with men. Knowing where to access testing for HIV on short notice was divided between participants with this knowledge (83\%) and those without. Having accessed different prevention services in the last twelve months such as free condoms, online or printed information on HIV/STI and having talked to a prevention worker were deemed to possibly affect the decisions to test for HIV and were therefore included.

\section{Logistic regression analysis}

Variables were analysed by univariate logistic regression and $t$-test to identify factors associated with having been tested for HIV during the last twelve months. Sixteen variables were tested for an association with having been tested for HIV during the last twelve months. Due to collinearity two variables, living with HIV and having tested for other STIs during the last 12 months, were excluded. The variables with a p-value below 0.05 were included in the final model. The Hosmer and Lemeshow test was used to check for goodness of fit. Included variables were checked for interactions, and no significant interaction was found.

\section{Ethical approval}

Ethical approval for this study was obtained from the Regional Ethical Review Board, Stockholm, Sweden
(Dnr 2013/248-31/3). Participation was anonymous and no personal identification data were collected. Informed consent was provided by all participants after having read the study information by an active click to confirm participation. Parental consent was not sought for participants as the Swedish regulations regarding ethical trial for research among humans states that the age of consent is 15 years old in Sweden [24]. The consent procedure was approved by the Regional Ethical Review Board, Stockholm, Sweden.

\section{Results}

Sociodemographic characteristics of the study population The median age of participants was 36 years, further details are reported in Table 1 . Over half (57\%) had tertiary education and $67 \%$ were employed. Median time spent living in Sweden was 15 years, ranging from less than one year to 58 years. Over half (57\%) held Swedish citizenship, 25\% had a permanent residency permit and $0.4 \%$ was in the process of seeking asylum. Most (58\%) were born in Europe, a fifth were born in Asia (20\%), about a tenth in South America (11\%) and North and Central America (9\%) respectively. Lastly, a small numbers of participants were born in Africa (1\%).

\section{Sexual identity and behaviour}

The majority (64\%) identified as homosexual as reported in Table 2 . Half (50\%) reported being single, $35 \%$ were in a relationship with a man and $9 \%$ with a woman. The median number of sexual partners during the last twelve months was three. About 10\% reported having had sex with both men and women during the last twelve months. Frequency of male partners for UAI was on average 2.5 , and the median was 0 .

\section{HIV/STI testing experience}

Close to half (45\%) had been tested for HIV during the last twelve months, an additional third had been tested at some time and a fifth reported never having been tested for HIV (See Table 2). Participant experience of having tested for HIV during the last 12 months showed a declining trend with increased years of stay in Sweden, as shown in Fig. 1. In addition, participant experience of having tested for HIV during the last 12 months varied with age peaking at 28 year old, as shown in Fig. 2.

Self-reported HIV prevalence among participants was $4 \%$. The majority $(88 \%)$ felt certain regarding their HIV serostatus, while $11 \%$ reported being uncertain. Almost a fifth $(17 \%)$ reported not knowing where to be tested for HIV. Among those who had never been tested for HIV, the most common reason given was that'I've never thought of it' or the belief that'I don't take risks'. While a fifth of those who had never been tested reported that 
Table 1 Sociodemographic characteristics, sexual orientation and behaviour among participants

\begin{tabular}{|c|c|c|c|}
\hline Variable & & $\begin{array}{l}\text { Mean/Median or } \\
\text { Percentage }\end{array}$ & $\mathrm{N}$ \\
\hline Age & & $38 / 36(16-73)$ & 243 \\
\hline \multirow[t]{5}{*}{ Residential area } & Stockholm region & $26.7 \%$ & $64 / 240$ \\
\hline & Gothenburg region & $12.5 \%$ & $30 / 240$ \\
\hline & Malmö region & $11.3 \%$ & $27 / 240$ \\
\hline & City with $>10000$ inhabitants & $37.1 \%$ & $89 / 240$ \\
\hline & Town or rural region with $<10000$ inhabitants & $12.5 \%$ & $30 / 240$ \\
\hline \multirow[t]{4}{*}{ Education } & $\begin{array}{l}\text { Not completed primary or lower-secondary level } \\
\text { education }\end{array}$ & $1.2 \%$ & $3 / 244$ \\
\hline & Primary or lower-secondary level education & $3.7 \%$ & $9 / 244$ \\
\hline & $\begin{array}{l}\text { Upper-secondary education level or vocational } \\
\text { training }\end{array}$ & $38.5 \%$ & $94 / 244$ \\
\hline & University education & $56.6 \%$ & $\begin{array}{l}138 / \\
244\end{array}$ \\
\hline \multirow[t]{5}{*}{ Occupation } & Employed & $68.3 \%$ & $\begin{array}{l}166 / \\
243\end{array}$ \\
\hline & Student & $15.6 \%$ & $38 / 243$ \\
\hline & Unemployed & $6.2 \%$ & $15 / 243$ \\
\hline & Retired & $4.9 \%$ & $12 / 243$ \\
\hline & Long-term sick leave & $4.9 \%$ & $12 / 243$ \\
\hline Years lived in Sweden & & $18 / 15(0-58)$ & 241 \\
\hline \multirow[t]{4}{*}{ Years lived in Sweden by group } & $0-5$ & $27.8 \%$ & $67 / 241$ \\
\hline & $>5-10$ & $14.1 \%$ & $34 / 241$ \\
\hline & $>10-15$ & $7.9 \%$ & 19/241 \\
\hline & $>15-58$ & $50.2 \%$ & $\begin{array}{l}121 / \\
241\end{array}$ \\
\hline \multirow[t]{8}{*}{ Citizenship status } & Swedish citizenship & $56.6 \%$ & $\begin{array}{l}137 / \\
242\end{array}$ \\
\hline & Permanent residence permit & $25.2 \%$ & $61 / 242$ \\
\hline & European citizenship & $1.2 \%$ & $3 / 242$ \\
\hline & Nordic citizenship & $1.7 \%$ & $4 / 242$ \\
\hline & Work permit/Student visa & $8.7 \%$ & $21 / 242$ \\
\hline & On-going asylum process & $0.4 \%$ & $1 / 242$ \\
\hline & Other & $1.7 \%$ & $4 / 242$ \\
\hline & Do not want to answer & $4.5 \%$ & $11 / 242$ \\
\hline \multirow[t]{5}{*}{ Reasons for moving to Sweden } & To work & $22.5 \%$ & $49 / 218$ \\
\hline & To study & $17.4 \%$ & $38 / 218$ \\
\hline & To be with partner/spouse/cohabitant & $15.6 \%$ & $34 / 218$ \\
\hline & To be with relatives & $23.9 \%$ & $52 / 218$ \\
\hline & To seek asylum & $20.6 \%$ & $45 / 218$ \\
\hline \multirow[t]{6}{*}{ Region of birth } & Africa & $1.2 \%$ & $3 / 244$ \\
\hline & Asia & $20.1 \%$ & $49 / 244$ \\
\hline & Europe except Sweden & $58.2 \%$ & $\begin{array}{l}142 / \\
244\end{array}$ \\
\hline & North \& Central America & $9.4 \%$ & $23 / 244$ \\
\hline & Oceania & 0 & $0 / 244$ \\
\hline & South America & $11.1 \%$ & $27 / 244$ \\
\hline
\end{tabular}


Table 1 Sociodemographic characteristics, sexual orientation and behaviour among participants (Continued)

\begin{tabular}{|c|c|c|c|}
\hline \multirow[t]{5}{*}{ Sexual orientation } & Homosexual & $63.9 \%$ & $\begin{array}{l}156 / \\
244\end{array}$ \\
\hline & Bisexual & $22.5 \%$ & $55 / 244$ \\
\hline & Heterosexual & $2.5 \%$ & $6 / 244$ \\
\hline & No category/Other & $10.2 \%$ & $25 / 244$ \\
\hline & Don't know & $0.8 \%$ & $2 / 244$ \\
\hline \multirow[t]{4}{*}{ Relationship with } & No one & $49.6 \%$ & $\begin{array}{l}120 / \\
242\end{array}$ \\
\hline & Man & $34.4 \%$ & $84 / 242$ \\
\hline & Woman & $9.4 \%$ & $23 / 242$ \\
\hline & Several persons of which at least one is a man & $6.2 \%$ & $15 / 242$ \\
\hline No. of sexual partners last 12 months & & $8.8 / 3(0-100)$ & 200 \\
\hline $\begin{array}{l}\text { Having had unprotected sex with men and women last } \\
12 \text { months }\end{array}$ & & $9.2 \%$ & $22 / 240$ \\
\hline No. of casual male sex partners for UAl last 12 months & & $2,5 / 0(0-100)$ & 193 \\
\hline Member of LGBTI organisation & & $36.5 \%$ & $80 / 219$ \\
\hline
\end{tabular}

they didn't know where to access HIV-testing, 2\% reported having been denied a HIV test by health personnel.

$37 \%$ reported having been tested for STIs during the last twelve months. A third reported never having been tested for STIs. About a third had been tested for both HIV and STIs during the last 12 months as shown in Fig. 3.

\section{HIV/STI prevention services used and requested by participants}

Most participants reported having read online (66\%) and printed (54\%) information on HIV/STI during the past 12 months. Half (51\%) had received free condoms and about a third (37\%) had talked about HIV/STI with a prevention worker during the same time period.

The majority $(76 \%)$ requested a rapid test for HIV and easily accessible condoms and lubricants in places where MSM meet. In addition, there were requests for anonymous HIV testing (69\%), MSM-friendly clinics (68\%), HIV/STI testing outside of the healthcare setting (63\%), vaccination for hepatitis A, B (66\%) and HPV (63\%) and the availability of condoms and lubricants by mail (63\%). Over half (58\%) requested web-based HIV/STI information.

About half (48\%) requested individual counselling regarding HIV/STI and safe sex, 39\% requested online counselling on these issues and 34\% group counselling. 38\% requested SMS reminder for HIV/STI-testing, 37\% requested pamphlets on HIV/STI and safe sex and 31\% requested support groups to deal with sexuality and health.

\section{Associations with having been tested for HIV during the past twelve months}

The univariate analysis results are presented in Table 3. The following variables were found to be significantly associated with having been tested for HIV during the last 12 months: lived in Sweden for less than or equal to 5 years (OR 1.87, 95\%CI 1.04-3.36), knowledge of where to get tested for HIV (OR 2.21, 95\%CI 1.03-4.74), talked about HIV/STI with a prevention worker during the last 12 months (OR 5.33 95\%CI 2.94-9.65), received free condoms during the last 12 months (OR 2.23, 95\%CI 1.20-3.82), read online about STI/HIV during the last 12 months (OR 2-56, 95\%CI 1.42-4.60), and read printed information about HIV/STI during the last 12 months (1.86, 95\%CI 1.09-3.19).

After multivariate adjustment, lived in Sweden for less than or equal to 5 years (aOR 2.12 95\%CI 1.07-4.18) and talked to a HIV/STI prevention worker during the last 12 months (aOR 4.6 95\%CI 1.28-9.29) remained significantly associated with having tested for HIV in the past 12 months.

\section{Discussion}

About half of the foreign-born MSM participants in this study had been tested for HIV during the last twelve months. Participants who had lived in Sweden less than or equal to 5 years were more likely to have been tested for HIV during the last 12 months. Having talked about HIV/STI with a prevention worker during the past year was associated with having been tested for HIV.

Initially, after moving to Sweden, access to HIV testing in an MSM-competent, non-stigmatizing environment may encourage frequent testing. Protected gay rights and experience of the Swedish gay community might enable disclosure as an MSM to health care staff. This may increase the likelihood of being offered HIV testing regularly. In addition, as a person migrates to a new setting, new sexual relationships may take place that motivate the individual to get tested. Easy access to HIV/STI testing is 
Table 2 HIV/STI testing experience among participants

\begin{tabular}{|c|c|c|c|}
\hline \multicolumn{2}{|l|}{ Variable } & \multirow{2}{*}{$\begin{array}{l}\text { Percentage } \\
45.4 \%\end{array}$} & \multirow{2}{*}{$\frac{N}{104 / 229}$} \\
\hline Most recent HIV test & Last 12 months & & \\
\hline & $>12$ months & $32.8 \%$ & $75 / 229$ \\
\hline & Never & $19.7 \%$ & $45 / 229$ \\
\hline & Don't remember & $2.2 \%$ & $5 / 229$ \\
\hline \multirow[t]{4}{*}{ Self-reported HIV status } & Living with HIV & $3.9 \%$ & $9 / 228$ \\
\hline & Negative & $84.2 \%$ & $192 / 228$ \\
\hline & Uncertain & $10.5 \%$ & $24 / 228$ \\
\hline & Don't want to answer & $1.0 \%$ & $3 / 228$ \\
\hline $\begin{array}{l}\text { Don't know where to get tested for HIV on } \\
\text { short notice }\end{array}$ & & $17.1 \%$ & $37 / 217$ \\
\hline \multirow{18}{*}{$\begin{array}{l}\text { Reasons for not testing among those never } \\
\text { tested for HIV }\end{array}$} & I believe that I have not taken any risks & $51.1 \%$ & $23 / 45$ \\
\hline & I don't know where to get tested & $22.2 \%$ & $10 / 45$ \\
\hline & I'm living in a monogamous relationship & $20.0 \%$ & $9 / 45$ \\
\hline & I'm afraid I will feel like a failure if I have HIV & $20.0 \%$ & $9 / 45$ \\
\hline & I'm afraid that staff or other visitors to the clinic will recognize me & $15.6 \%$ & $7 / 45$ \\
\hline & I'm afraid I will become ill & $15.6 \%$ & $7 / 45$ \\
\hline & Due to the rules in the Swedish Communicable Disease Act & $15.6 \%$ & $7 / 45$ \\
\hline & I'm afraid I will lose family and friends & $13.3 \%$ & $6 / 45$ \\
\hline & I don't trust confidentiality in the healthcare system & $11.1 \%$ & $5 / 45$ \\
\hline & I don't want to know my HIV status & $11.1 \%$ & $5 / 45$ \\
\hline & I'm afraid the test results would have a negative influence on my sex life & $11.1 \%$ & $5 / 45$ \\
\hline & Due to how the Swedish penal code is applied to HIV & $8.9 \%$ & $4 / 45$ \\
\hline & I'm afraid I will lose my partner & $8.9 \%$ & $4 / 45$ \\
\hline & It's difficult for me to get to a clinic & $6.7 \%$ & $3 / 45$ \\
\hline & I'm afraid the test results would affect my chances of staying in Sweden & $4.4 \%$ & $2 / 45$ \\
\hline & I'm afraid I will lose my job & $2.2 \%$ & $1 / 45$ \\
\hline & There is no cure for HIV, so I see no point in getting tested & $2.2 \%$ & $1 / 45$ \\
\hline & $\begin{array}{l}\text { I have been denied an HIV test by health personnel, even though I } \\
\text { wanted to get tested }\end{array}$ & $2.2 \%$ & $1 / 45$ \\
\hline \multirow[t]{4}{*}{ Most recent STI test } & Last 12 months & $37.0 \%$ & $84 / 227$ \\
\hline & $>12$ months & $26.9 \%$ & $61 / 227$ \\
\hline & Never & $33.0 \%$ & $75 / 227$ \\
\hline & Don't remember & $3.1 \%$ & $7 / 227$ \\
\hline \multirow[t]{12}{*}{ Self-reported STI diagnoses last 12 months } & Chlamydia & $6.3 \%$ & $9 / 144$ \\
\hline & Gonorrhoea & $4.2 \%$ & $6 / 144$ \\
\hline & Syphilis & $0.7 \%$ & $1 / 144$ \\
\hline & Condyloma/HPV & $0.7 \%$ & $1 / 144$ \\
\hline & Hep A & $0.7 \%$ & $1 / 144$ \\
\hline & Нер B & $0.7 \%$ & $1 / 144$ \\
\hline & Mycoplasma & $0.7 \%$ & $1 / 144$ \\
\hline & Hepatitis C & 0 & $0 / 144$ \\
\hline & Genital herpes & 0 & $0 / 144$ \\
\hline & Lymphogranuloma venereum & 0 & $0 / 144$ \\
\hline & No STI & $88.9 \%$ & $128 / 144$ \\
\hline & Don't know & $1.4 \%$ & $2 / 144$ \\
\hline
\end{tabular}




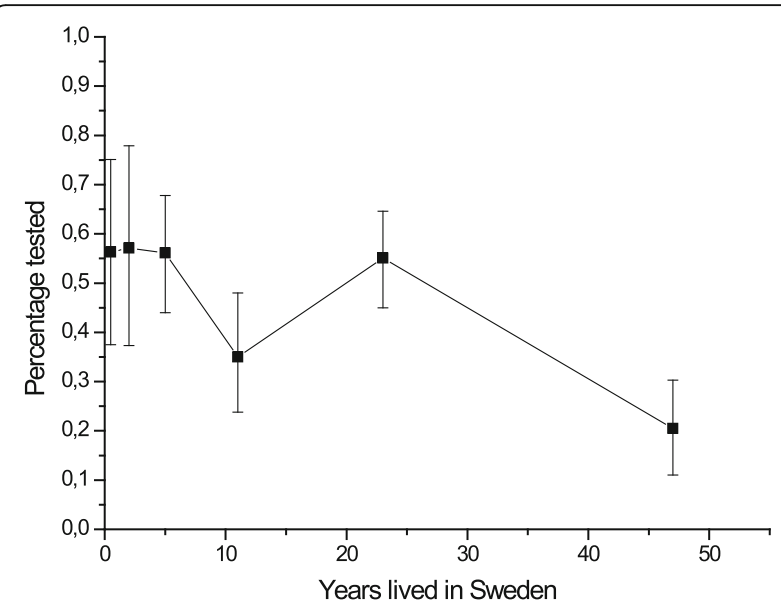

Fig. 1 Participants' experience of having been tested for HIV during the last 12 months in relation to how long they have lived in Sweden

common in urban areas in Sweden, which may increase the frequency of testing $[25,26]$.

The European MSM Internet Survey (EMIS) was conducted in 2010 as an online banner survey among 3,089 MSM living in Sweden and reported that 30\% had been tested for HIV during the last 12 months, in comparison to $45 \%$ in this study [12]. As both studies report on convenience samples of MSM, they cannot be compared and conclusions to the wider population of MSM living in Sweden cannot be made. However it is interesting to note that HIV-testing rates during the last 12 months among the foreign-born MSM participants in this study is still slightly higher than the most recent estimates reported among MSM in Sweden mentioned above.

Twenty percent of participants reported never having been tested for HIV. The EMIS 2010 study found that $25 \%$ of MSM living in Sweden had never been tested for

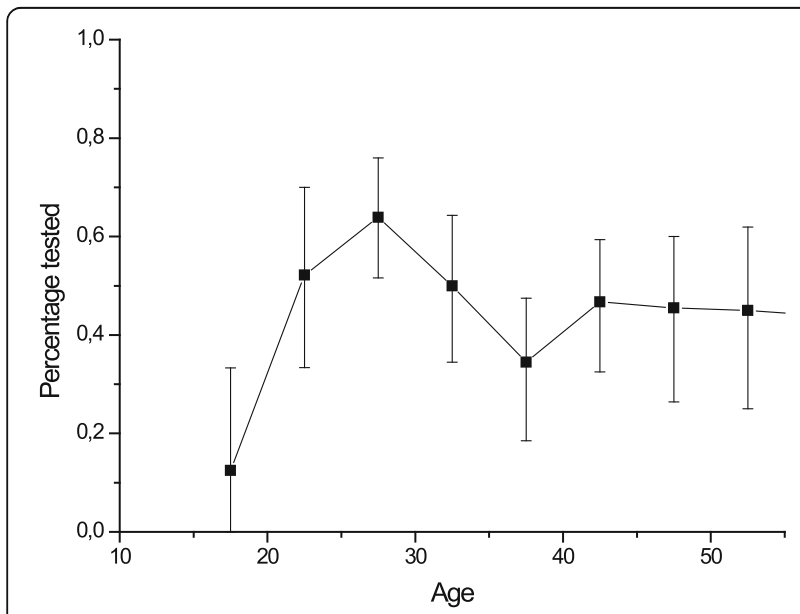

Fig. 2 Participants' experience of having been tested for HIV during the past 12 months in relation to their age

\section{$\square$ None $\square$ HIV-test $\square$ STI-test $\square$ Both HIV and STI-test}

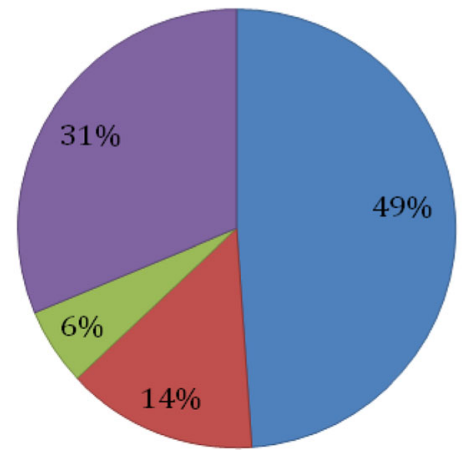

Fig. 3 Experience of HIV and STI testing during the past 12 months among participants

HIV [12]. Further, a study from Britain report that migrant MSM are more likely to have been tested for HIV than MSM born in Britain [27]. One of the most common reasons given for never having been tested for HIV was low perceived risk. Similar findings have been reported among MSM that had never been tested for HIV in Spain [28]. The perceived low risk may be correct, however, it could also be based on inadequate knowledge of HIV transmission among MSM. As participants reported being men who have sex with men they do belong to the group with the highest number of newly diagnosed cases of HIV per year in Sweden. Further research is needed to understand how risk perception and HIV knowledge affects HIV-testing behaviour within this group.

Participants who had talked about HIV/STI with a prevention worker were more likely to have been tested for HIV, indicating that individual counselling and outreach work have an important role in prevention work for foreign-born MSM. A number of HIV testing services were requested by study participants, increasing access to these services might increase HIV testing rates. HIV rapid test, anonymous HIV testing, HIV/STI testing outside of the health care setting and MSM-friendly clinics were requested by the majority of participants and should be a priority in HIV prevention. Making condoms and lubricants easily available in places where MSM meet may increase condom use. Internet-based HIV/STI information interventions were favoured by most, and this finding is consistent with a previous study from 2012 [29].

Increasing HIV testing is crucial for HIV prevention, decreasing the number of undiagnosed people living with HIV is a priority globally and most important to ensure access to treatment for those living with HIV [5]. Biomedical HIV prevention interventions are serostatusdependent such as treatment as prevention (TasP), post- 
Table 3 Associations with HIV testing during last 12 months among participants

\begin{tabular}{|c|c|c|c|}
\hline \multicolumn{2}{|l|}{ Variable } & \multicolumn{2}{|c|}{ HIV test during last 12 months } \\
\hline & & Univariate OR (95\%Cl) & Multivariate OR $(95 \% \mathrm{Cl})$ \\
\hline \multirow[t]{3}{*}{ Age } & $<25$ & $0.85(0.40-1.83)$ & \\
\hline & $25-40$ & $1.53(0.91-2.59)$ & \\
\hline & $<40$ & $0.69(0.40-1.18)$ & \\
\hline \multicolumn{2}{|c|}{ Tertiary education vs. lower } & $1.59(0.94-2.70)$ & \\
\hline \multirow[t]{5}{*}{ Occupation } & Employed & $0.95(0.70-1.30)$ & \\
\hline & Unemployed & $0.70(0.24-2.06)$ & \\
\hline & Long-term sick-leave & $0.45(0.11-1.81)$ & \\
\hline & Student & $0.74(0.35-1.56)$ & \\
\hline & Retired & $0.53(0.15-1.82)$ & \\
\hline \multicolumn{2}{|c|}{ Years lived in Sweden $<=5$ years vs. $>5$ years } & $1.87(1.04-3.36)^{*}$ & $2.12(1.07-.4 .18)^{*}$ \\
\hline \multicolumn{2}{|c|}{ Seeking asylum as reason for coming to Sweden vs. other reasons for migration } & $1.18(0.59-2.38)$ & \\
\hline \multicolumn{2}{|c|}{ Having had UAI with casual partner in the past 12 months vs. not } & $0.75(0.41-1.38)$ & \\
\hline \multicolumn{2}{|c|}{ Single vs. being in a relationship } & $0.85(0.50-1.43)$ & \\
\hline \multicolumn{2}{|c|}{ Having had unprotected sex with men and women during last 12 months vs. only men } & $0.88(0.34-2.28)$ & \\
\hline \multicolumn{2}{|c|}{ Knowledge of where to get tested for HIV on short notice vs. no such knowledge } & $2.21(1.03-4.74)^{*}$ & $2.01(0.88-4.80)$ \\
\hline \multicolumn{2}{|c|}{ LGBTI organization member vs. not } & $0.76(0.36-1.59)$ & \\
\hline \multicolumn{2}{|c|}{ Talked about HIV/STI with a prevention worker during last 12 months vs. not } & $5.33(2.94-9.65)^{*}$ & $\begin{array}{l}4.6(2.28- \\
.9 .29)^{*}\end{array}$ \\
\hline \multicolumn{2}{|c|}{ Received free condoms during last 12 months vs. not } & $2.23(1.30-3.82)^{*}$ & $1.46(0.77-2.76)$ \\
\hline \multicolumn{2}{|c|}{ Read online about STI/HIV during last 12 months vs. not } & $2.56(1.42-4.60)^{*}$ & $1.73(0.81-3.70)$ \\
\hline \multicolumn{2}{|c|}{ Read printed information about HIV/STI during last 12 months vs. not } & $1.86(1.09-3.19)^{*}$ & $0.71(0.33-1.51)$ \\
\hline
\end{tabular}

* $p$-value $<0.05$

exposure prophylaxis (PEP), and pre-exposure prophylaxis (PrEP) $[5,30]$. In addition, knowledge of serostatus facilitates tailored behavioural and educational interventions. Delayed diagnosis of HIV is associated with poorer response to antiretroviral therapy and a higher risk for morbidity and mortality [5, 31]. A 45\% annual HIV-testing rate among foreign-born MSM may be too low to detect those in need of antiretroviral treatment. Being undiagnosed with HIV for long time periods and unaware of the risk of transmission, may increase the risk of sexual transmission due to not receiving treatment and thereby not achieving viral suppression.

The data reported here have limitations, such as being self-reported, which may introduce reporting bias [32, 33]. Efforts to decrease reporting bias included an easy to answer online questionnaire, which was answered anonymously. The survey was available in Swedish and English thereby excluding foreign-born MSM who were not conversant in those languages. As the survey was conducted online on a Web community, MSM who were not members were not able to participate. Since the participants were not randomly selected, it is not possible to generalize results to wider groups of foreign-born MSM living in Sweden. The survey is of cross-sectional design and causality can therefore not be detected. Nonetheless, the data provide important insights into this heterogeneous, at risk of HIV and hard to reach group. Furthermore, half of the sample had lived in Sweden for fifteen years or longer, and less than one per cent were in the asylum-seeking process. There is a need for further studies to explore health needs among foreign-born MSM who are seeking asylum.

\section{Conclusions}

Efforts are needed to promote HIV testing among foreignborn MSM. Peer outreach, individual and group counselling may be preferred interventions to do so. In addition, it is critically important to increase HIV testing among foreignborn MSM who have lived in Sweden for more than 5 years. Further research should explore if scale up of implementation of the requested services; HIV rapid tests, HIV testing outside of the health care setting, anonymous HIV testing and MSM-friendly clinics, may increase frequency of HIV-testing and detection of new cases linked to treatment among foreign-born MSM living in Sweden.

\section{Acknowledgements}

The authors would like to express our sincere thanks to the study participants.

\section{Funding}

The Public Health Agency of Sweden provided funding for this study and took part in study design discussions. The funders did not participate in data analysis, interpretation of data and writing the manuscript. 


\section{Availability of data and materials}

The data used and analysed in this study will be made available by the corresponding author on reasonable request.

\section{Author's contributions}

KIP and BF developed the web-survey, with support from AT and SS. SS, BF, $F L, A T$, and KIP all participated in designing the here presented study and analysis plan. SS and FL performed the data analyses, and analyses were reviewed by AT, KIP, and BF. SS drafted the first version of the manuscript. All authors contributed to the text in the manuscript, read and approved the final manuscript for submission.

\section{Competing interests}

The authors declare that they have no competing interests.

\section{Consent for publication}

Not applicable.

\section{Ethics approval and consent to participate}

Ethical approval for the study was obtained from the Regional Ethical Review Board, Stockholm, Sweden (Dnr 2013/248-31/3). Participation was anonymous and no personal identification data were collected. Informed consent was provided by all participants after having read the study information by an active click to confirm participation. The consent procedure was approved by the Regional Ethical Review Board, Stockholm, Sweden.

\section{Author details}

'Department of Public Health Sciences, Karolinska Institutet, Tomtebodavägen 18a, floor 4, SE-171 77 Stockholm, Sweden. ${ }^{2}$ Department of Sociology, Stockholm University, SE-106 91 Stockholm, Sweden.

\section{Received: 5 December 2015 Accepted: 23 December 2016}

Published online: 31 January 2017

\section{References}

1. United Nations, Department of Economic and Social Affairs, Population Division: International Migrant Report 2013. In. Edited by United Nations Department of Economic and Social Affairs, Population Division. United Nations database, POP/DB/MIG/Stock/Rev.2013/Age; 2013.

2. Population statistics. [http://www.scb.se/en/finding-statistics/statistics-bysubject-area/population/population-composition/population-statistics/]. Accessed 14 Sept 2015.

3. International Organization for Migration (IOM). World Migration Report 2013 Geneva: Publisher International Organization for Migration (IOM); 2013. [https:/www.iom.int/wmr2013]. Accessed 14 Sept 2015.

4. International Lesbian G, Bisexual, Trans and Intersex Association, Carroll A, Itaborahy LP. State Sponsored Homophobia, A world survey of laws: criminalisation, protection and recognition of same-sex love. Geneva: ILGA; 2015.

5. European Centre for Disease Prevention and Control (ECDC). HIV and ST prevention among men who have sex with men. Stockholm: Publisher European Centre for Disease Prevention and Control (ECDC); 2015.

6. Beyrer C, Baral SD, van Griensven F, Goodreau SM, Chariyalertsak S, Wirtz AL, Brookmeyer R. Global epidemiology of HIV infection in men who have sex with men. Lancet. 2012;380(9839):367-77.

7. Europe ECfDPaCaWHOROf: HIV/AIDS Surveillance in Europe 2013. In: Surveillance report. Stockholm: European Centre for Disease Prevention and Control; 2014

8. Alvarez-del Arco: HIV Acquisition among Migrants Living in Europe: Results from aMASE - Advancing Migrant Access to Health Services in Europe. In: Fifteenth European AIDS Conference. Barcelona, Spain; 2015

9. Perez-Molina JA, Lopez-Velez R, Navarro M, Perez-Elias MJ, Moreno S. Clinicoepidemiological characteristics of HIV-infected immigrants attended at a tropical medicine referral unit. J Travel Med. 2009;16(4):248-52. 210. 1111/j.1708-8305.2009.00308.x.

10. Swedish Institute for Infectious Disease Control (SMI). Global AIDS response: progress report 2012. Stockholm: Swedish Institute for Infectious Disease Control; 2012

11. Folkhälsomyndigheten. MSM2013 - En studie om sex, hiv och hälsa bland män som har sex med män i Sverige. Stockholm: Public Health Agency of Sweden; 2015.
12. Swedish Institute for Infectious Disease Control (SMI): EMIS 2010 Sverige. In. Stockholm, Sweden; 2013.

13. Tikkanen RH: MSM-enkäten 2006: Person, Relation och Situation. In. Edited by 2008:1 FR: Malmö Högskola; 2008 .

14. Tikkanen RH: MSM-enkäten 2008: Riskhandlingar, hivtest och preventiva behov bland män som har sex med män. In. Edited by 2010:4 Fr. Malmö, Sweden: Malmö Högskola; 2010

15. Lewis F, Hughes GJ, Rambaut A, Pozniak A, Leigh Brown AJ. Episodic sexual transmission of HIV revealed by molecular phylodynamics. PLoS Med. 2008; 5(3):e50. doi:10.1371/journal.pmed.0050050.

16. McKeown E, Doerner R, Nelson S, Low N, Robinson A, Anderson J, Elford J. The experiences of ethnic minority MSM using NHS sexual health clinics in Britain. Sex Transm Infect. 2012;88(8):595-600. doi: 510.1136/sextrans2011-050436. Epub 052012 Jun 050420.

17. Heckathorn DD. Respondent-driven sampling: a New approach to the study of hidden populations. Soc Probl. 1997;44:174-99.

18. Magnani R, Sabin K, Saidel T, Heckathorn D. Review of sampling hard-to-reach and hidden populations for HIV surveillance. AIDS (London, England). 2005;19 Suppl 2:567-72.

19. Qruiser. [https://www.qruiser.com]. Accessed 14 September 2015.

20. Persson Kl, Tikkanen R, Bergstrom J, Berglund T, Thorson A, Forsberg BC. Experimentals, bottoms, risk-reducers and clubbers: exploring diverse sexual practice in an Internet-active high-risk behaviour group of men who have sex with men in Sweden. Cult Health Sex. 2015:16:1-15.

21. Forskning och statistik om integration och migration i Sverige. [ http:// www.migrationsinfo.se/arbetsmarknad/sysselsattning/ ]. Accessed 14 Sept 2015

22. Erbjudande om hälsoundersökning. [http://www.socialstyrelsen.se/ vardochomsorgforasylsokandemedflera/halsoundersokning]. Accessed 6 Sept 2015.

23. Baggaley RF, White RG, Boily MC. HIV transmission risk through anal intercourse: systematic review, meta-analysis and implications for HIV prevention. Int J Epidemiol. 2010;39(4):1048-63.

24. Riksdag S: Etikprövning av forskning som avser människor Lag (2003: 460) In.; 2003.

25. Här testar du dig. [http://www.rfsu.se/sv/Sex-relationer/Konssjukdomar-ochhiv/Har-testar-du-dig//. Accessed 9 Sept 2015.

26. [https://www.sentry.nu/testa-mig/]. Accessed 1 Dec 2015.

27. Elford J, Doerner R, Mckeown E, Nelson S, Anderson J, Low N. HIV infection among ethnic minority and migrant men who have sex with men in Britain. Sex Transm Dis. 2012;39(9):678-86. doi: 610.1097/OLQ. 1090b1013e31825c38018.

28. Hoyos J, Fernandez-Balbuena S, de la Fuente L, Sordo L, Ruiz M, Barrio G, Belza MJ. Never tested for HIV in Latin-American migrants and Spaniards: prevalence and perceived barriers. J Int AIDS Soc. 2013;16:18560. doi:10. 7448/IAS.7416.7441.18560.

29. Stromdahl S, Lu X, Bengtsson L, Liljeros F, Thorson A. Implementation of Web-based respondent driven sampling among Men Who have Sex with Men in sweden. PLoS One. 2015;10(10):e0138599. doi: 0138510.0131371/ journal.pone.0138599. eCollection 0132015.

30. Stromdahl S, Hickson F, Pharris A, Sabido M, Baral S, Thorson A: A systematic review of evidence to inform HIV prevention interventions among men who have sex with men in Europe. Euro Surveill 2015, 20(15).(pii):21096.

31. European AIDS Clinical Society: EACS Guidelines. 2014, Version 7.1

32. Jaccard JM, R. Wan, C. Dittus, P. Quinlan, S.: The Accuracy of Self-Reports of Condom Use and Sexual Behavior. Journal of Applied Social Psychology 2002(32, 9):pp. 1863-1905.

33. Weinhardt $L S$, Forsyth $A D$, Carey MP, Jaworski BC, Durant LE. Reliability and validity of self-report measures of HIV-related sexual behavior: progress since 1990 and recommendations for research and practice. Arch Sex Behav. 1998;27(2):155-80. 